\title{
TEXTILSKIN: as redes sociais digitais como apoio ao design de superfície
}

\author{
Lavínnia Seabra \\ Universidade Federal de Goiás \\ lavinniaufg@gmail.com \\ Evelise Anicet Ruthschilling \\ Universidade Federal do Rio Grande do Sul \\ eanicet@gmail.com
}

\begin{abstract}
Resumo: Esse artigo é resultado de reflexões defendidas em uma tese de doutorado. Foi realizado um recorte sobre o resultado alcançado; uma ferramenta digital denominada Textilskin, objetivo principal dessa investigação, e que gera módulos visuais exclusivos para serem utilizados de diferentes formas, como por exemplo: estampas. Trabalho que se utilizou de uma metodologia transdiciplinar e contextualizou possibilidades potenciais de desenvolvimento imagético, através da cocriação entre designer e público - usuário das redes digitais. Uma proposta possível de ser aplicada no Design de Superfície e que comprovou a ampliação no desenvolvimento de novas formas de trabalho para essa área.
\end{abstract}

Palavras-chave: cocriação, redes digitais, design de superfície.

Abstract: This article is the result of some reflections defended in the thesis. A clipping was made about the result achieved; a digital tool called Textilskin, main objective of this research, and generating modules exclusive visual to be used in different ways, for example: prints. Work that has been used a method transdisciplinary and contextualized potential possibilities development of imagery, through co-creation between designer and public - user of digital networks. A proposal can be applied in the Surface Design and proved that the expansion in the development of new forms of work for this area.

Keywords: cocreation; digital networks; surface design. 


\section{INTRODUÇÃO}

O processo de produção visual mudou consideravelmente com o advento das tecnologias digitais. Com a globalização, a internet e todas as suas potencialidades, como: as redes de interconexões digitais entre usuários, os aplicativos, os softwares e todos os dispositivos móveis eletrônicos inovadores, as possibilidades de transmissão, distribuição e criação da informação imagética ampliaram-se. Esses aspectos têm promovido possibilidades de trabalho coletivo, tendo como possíveis suportes as redes sociais digitais ${ }^{1}$ que são estruturas atualizadas por usuários conectados de diversos lugares com produção de informação em tempo real, com fluxo contínuo, sem um eixo definido. Ou seja, estamos diante de uma estruturação de processos abertos, auxiliados e alicerçados no espaço digital.

Desse modo, com essas facilidades potencializadas pela Internet, é possível encontrar práticas crescentes no desenvolvimento de atividades de criação coletiva, onde os usuários podem fazer parte de uma experiência diferenciada, como é o caso do QUIRKY ${ }^{2}$, por exemplo: o usuário posta uma ideia inicial - o desenvolvimento de um dispositivo para ligar vários aparelhos domésticos; à medida que novos usuários vão entrando e comentando, esse objeto que precisa ser voltado para o consumidor final, vai ganhando melhorias e sendo redesenhado. Nessa mesma estrutura de funcionamento, outro site interessante é o PROTAGONIZE ${ }^{3}$ - nele, um capítulo de livro é lançado e cada novo usuário poderá continuar o livro, construindo um novo capítulo. Contudo, nunca se saberá, ao certo, o final da história. Ainda, nessa mesma estrutura de trabalho, o de cocriação, o site WIKIPAINT ${ }^{4}$ proporciona aos usuários a experiência de, a múltiplas mãos, desenvolver elementos imagéticos que podem ser modificados, em tempo real, por outro usuário conectado no ambiente. São exemplos interessantes e que foram pesquisados ao longo do desenvolvimento da tese, durante o período de seleção das funções possíveis de serem inseridas na ferramenta gerada nessa tese.

Os autores Garton, Haythornthwaite e Welman (1997, p. 1, tradução nossa) afirmam que "quando uma rede de computadores conecta uma rede de pessoas e organizações, isso é uma rede social". Portanto, todo esse conteúdo refere-se àquilo que é trocado pelos pares envolvidos nos processos de interação. Ou seja, com a ampliação dos espaços sociais digitais, estamos vivenciando a transformação da infraestrutura comunicacional. Algo que está promovendo um novo ambiente produtivo e criativo. Noções como sociedade da informação e sociedade do conhecimento, redes de interconexões mediadas por computador, fazendo referência às pesquisas dos autores (CASTELLS, 2008; HAYTHORNTHWAITE, 2005 e RHEINGOLD 1996), reforçam a percepção de que estamos construindo um aglomerado de indivíduos hiperinformados e hipercomunicativos. Mas como destaca Judith Donath (1998), esse aspecto constrói uma realidade efêmera:

\footnotetext{
${ }^{1}$ Essas redes são padrões de conexão ampliados no ciberespaço, compreendidos por elementos fluídos que compõem grupos interconectados por nós formando diversas direções (RECUERO, 2009, p. 102).

2 https://www.quirky.com/Disponível em: <http://info.abril.com.br/noticias/mercado/site-de-criacao-coletivarende-ate-para-quem-comenta-23072012-11.shl> Acesso em 03/04/2014.

${ }^{3}$ http://www.protagonize.com/Disponível em: <http://info.abril.com.br/noticias/mercado/site-de-criacao-coletivarende-ate-para-quem-comenta-23072012-11.shl> Acesso em 03/04/2014.

4 http://wikipaint.org/Disponível em: <http://info.abril.com.br/noticias/mercado/site-de-criacao-coletiva-rendeate-para-quem-comenta-23072012-11.shl> Acesso em 03/04/2014.
} 
nomes são trocados temporariamente e características não são persistentes. Assim, "um dos mais importantes aspectos da cultura digital é que esse espaço codificado numericamente permite que as pessoas explorem papéis e relacionamentos que seriam fechados para elas (...) o anonimato encoraja" (DONATH, 1998, p. 2). De certo modo, essa nova forma de produção informacional digital tornou-se uma espécie de regra que rege o comportamento social contemporâneo. Nesse cenário, Deleuze e Guatarri (1995) contribuem formulando o conceito de desterritorialização, ideia que concerne a uma produção rizomática, sem território ou eixos definidos - espaços lisos. Não há mais um único centro de produção, mas, sim, um conjunto de ramificações que vão proliferando novos elementos, ideias e a própria informação.

Nesse contexto, a investigação desenvolvida para a construção da ferramenta digital mesclou procedimentos baseados na metodologia transdisciplinar; ou seja, uma pesquisa que se apropriou de informações oriundas de várias áreas, como: a do design, na enunciação do problema e geração de alternativas para criação de um produto; a experimentação dentro do laboratório de estamparia e colorimetria da UNIVERSIDADE DO MINHO/PT, utilizando o método qualitativo sobre os processos de estampagem utilizados na impressão dos módulos gerados pela Textilskin e o método de entrevista com os usuários colaboradores nesse trabalho. Ainda, para o desenvolvimento do site, o laboratório MÍDIA LAB do Instituto de Artes de Brasília, da UNIVERSIDADE DE BRASÍLIA, coordenado pela profa. Dra. Suzete Venturelli, auxiliou nos testes das possibilidades que os programas - JavaFx e Flash poderiam proporcionar para a estruturação do site Textilskin. Tudo dentro de uma metodologia adaptativa, cujo grupo de trabalho e o próprio trabalho vão se adaptando às mudanças que ocorrem. Outros testes de impressão foram realizados dentro do laboratório de impressão da FACULDADE DE ARTES VISUAIS, da UNIVERSIDADE FEDERAL DE GOIÁS, e em duas empresas que prestam serviços de impressão digital, serigráfica e de corte a laser na cidade de Goiânia/GO. Para concretização das conclusões da tese foram considerados os índices de qualidade das imagens geradas pelo sistema, qualidade de impressão e resistência à luz.

\section{COCRIAÇÃO: processo que gera novas experiências}

O conceito de cocriação ou cocreation apareceu nos anos 2000, possivelmente oriundo dos desdobramentos do conceito de coprodução desenvolvido nos anos de 1970. Segundo os autores Prahalad \& Ramaswamy, 2004, a cocriação versa sobre a possibilidade de aproximar ou promover a interação entre empresa e consumidor criando o valor da empresa pelo consumidor; permitindo que o consumidor coconstrua uma experiência de serviço para a empresa se adequando ao seu contexto; unificando problemas e suas resoluções; criando experiências e diálogos de forma a possibilitar uma estrutura personalizada e integrada; sendo, assim, diversificadas (PRAHALAD \& RAMASWAMY, 2004, p. 8).

Contudo, para Franco 2010, a ideia de cocriação se manifesta, potencialmente aplicável, com a tecnologia da informação. Assim, um dos primeiros e bons exemplos sobre cocriação é a própria Wikipédia que apresenta vários significados construídos pelos usuários. Ainda, para o mesmo autor, a cocriação é idear e projetar interativa e coletivamente propostas que converjam para um mesmo ponto. Ou seja, algo que, quando distribuído, provoca novas mudanças que 
instigam outros a fazerem parte desse processo. Para ele, a cocriação é basicamente isso:

“[...] um processo composto por tentativas recorrentes de estabelecer e restabelecer congruências múltiplas e recíprocas entre ideias que mutam quando interagem, nem sempre se aproximando e se fundindo, mas frequentemente se distanciando e que podem ser novamente modificadas na interação para se combinar e reagir "quimicamente" umas com as outras em novas combinações gerando novas "substâncias" (novas ideias substantivas)" (FRANCO, sem página, 2012).

São possibilidades de abertura a novas interações em constante processo entre usuários, que incluem o desafio de construir outros cotidianos, buscando dialogar e compreender as múltiplas dimensões de uma nova realidade expandida pela tecnologia da informação. Os trabalhos colaborativos são, nesse contexto, processos em construção constante. Cada usuário, com papel de colaborador e interagente, é responsável pela construção de novas materializações das ideias. Por meio das facilidades proporcionadas pelas tecnologias interativas digitais, cada interator estabelece novas ligações com a universalidade de um grupo de sujeitos com aspectos diversificados. Em constante processo, os resultados dessa construção colaborativa são conjuntos de elementos propostos pela individualidade de cada colaborador, mas, que inseridos num espaço coletivo, expandem-se, transformando em propostas visuais plurais com aspectos muito peculiares.

\subsection{Cocriação visual mediada pelas redes interativas digitais}

A pesquisa verificou que esse fenômeno já vem ocorrendo em algumas redes sociais digitais, como por exemplo, o Wikipaint. Contexto em que se encontrou a questão que motiva o presente trabalho: seria possível afirmar a cocriação como uma metodologia de trabalho eficaz para a produção visual passível de aplicação no Design de Superfície?

As redes sociais digitais conhecidas hoje, por ORKUT, MySpace, DIÁSPORA e outras resultantes de uma aceleração tecnológica oriunda da WEB $2.0^{5}$, têm encontrado cada vez mais fôlego para ampliarem suas possibilidades de entretenimento e criação de novidades de forma coletiva e expandida. Entretanto, como afirmam Santaella e Lemos (2010), com o lançamento das redes com possibilidade de cooperações, inicia-se a Era das RSIs 3.0 $0^{6}$ - sistemas operacionais com

\footnotetext{
5 "A Web 2.0 é a segunda geração de serviços online e caracteriza-se por potencializar as formas de publicação, compartilhamento e organização de informações, além de ampliar os espaços para a interação entre os participantes do processo. A Web 2.0 refere-se não apenas a uma combinação de técnicas informáticas (serviços Web, linguagem Ajax, Web syndication, etc.), mas também a um determinado período tecnológico, a um conjunto de novas estratégias mercadológicas e a processos de comunicação mediados pelo computador. Este artigo dedicarse-á a esta última dimensão, sem que se possa descartar a inter-relação entre todas aquelas listadas" (PRIMO, Alex. O aspecto relacional das interações na Web 2.0. E- Compós (Brasília), v. 9, p. 1-21, 2007. Disponível em: < http://www.ufrgs.br/limc/PDFs/web2.pdf> Acesso em 23/03/2014.

6 "Espaços "multimodais" - abertura para tudo e para todos, com ferramentas diversificadas, como é possível encontrar, por exemplo, em uma das últimas atualizações realizadas pelo FACEBOOK, o aplicativo denominado de "a linha do tempo" (SANTAELLA, 2010, p. 23).
} 
ferramentas mais eficazes para a interação entre sujeitos, serviços e interação em tempo real. Há, então, uma transformação do tempo e do espaço, agora com um fluxo sociocultural exagerado, que Castells (2008) denomina "cultura do efêmero". A partir de narrativas pessoais, o que encontramos é uma produção eficaz de conteúdos que também podem contribuir para a formação da opinião coletiva. De certo modo, portanto, desenvolver propostas de trabalhos que possam ter como suporte e serem exploradas junto a essas estruturas de interconexões mediadas por dispositivos digitais, são o desafio contemporâneo. E, experiências como o CAMISETERIA ${ }^{7}$ ou a já citada WIKIPAINT são realidades de trabalho de criações visuais sui generis que ocorrem, ou em parte, ou totalmente, via processo coconstrutor.

Pensar na ampliação dessa forma contemporânea de trabalho, tendo como fonte principal as redes de interação social mediadas por computador, aplicadas e utilizadas como facilitadores no Design de Superfície, é possível vislumbrar impactos significativos tanto no desenvolvimento de ideias visuais quanto em diferentes possibilidades de experiências criativas para o desenvolvimento de projetos inovadores.

Algumas das várias potencialidades de ampliação na utilização da ideia de cocriação visual como mais uma forma de trabalho para o Design de Superfície, estão os aspectos como agilidade no processo de criação, personalização constante de imagens ou ideias visuais, contribuição de profissionais de diversas áreas situados em qualquer parte do mundo, flexibilidade na articulação de ferramentas, criação possível em qualquer lugar, desterritorializada, e, ao mesmo tempo, representativa do público online auxiliada por dispositivos móveis acessados à internet, entre outros aspectos.

\section{DESIGN DE SUPERFÍCIE: uma área em grande ascensão}

O termo Surface Design foi cunhado com o surgimento da Surface Design Association - SDA, em 1977, nos Estados Unidos, como uma decorrência da arte e do design têxtil. Foi trazido para o Brasil pela designer Renata Rubim no fim dos anos 80 . No I Encontro Nacional de Design de Superfície, ocorrido em 1991, em Porto Alegre, RS, foi decidido em assembleia, se utilizar a expressão Design de Superfície no Brasil, com uma concepção mais ampla, estendendo a superfícies de todos os materiais e também em ambientes virtuais. Em 2005, o CNPq reconheceu o Design de Superfície como uma especialidade do design no Brasil.

No Núcleo de Design de Superfície da UNIVERSIDADE FEDERAL DO RIO GRANDE DO SUL - NDS, fundado em 1998 e coordenado pela professora e designer Dra. Evelise Anicet Ruthschilling, que as discussões e pesquisas sobre essa área têm proporcionado um trabalho investigativo denso e difundido por todo o país e exterior.

\footnotetext{
"A superfície é compreendida como ente bidimensional porque se apresenta com características de plano, que pode estar descolado de outro objeto e assumir forma livre, expressando sempre o desdobramento de um plano no espaço. Por exemplo, as esculturas em chapas de ferro, elas possuem consistência física para garantir

${ }^{7}$ Site de comercialização de camisetas com desenvolvimento de estampas propostas pelos próprios consumidores. Disponível em: < http://www.camiseteria.com/> Acesso em: 02/04/2014.
} 
sua existência como objeto, mas sua maior característica é o material em duas dimensões que será sempre muitas vezes maior que a terceira dimensão que poderá haver, comumente percebidas como texturas táteis, ou até relevos, mas sempre bidimensionais", como nos coloca a pesquisadora de design de superfície Evelise Anicet Ruthschilling, em entrevista pessoal (Porto Alegre, março, 2014).

Portanto, dentro desse contexto, o Design de Superfície é uma atividade criativa que tem crescido muito nos últimos anos, devido a uma demanda do mercado crescente por inovação no desenvolvimento de objetos cotidianos diversificados que explorem novas texturas e tecnologias que estão surgindo. Como a professora ainda afirma: O Design de Superfície hoje não se limita à inserção de desenhos, cores e texturas sobre um substrato, mas à função principal de conferir qualidades às superfícies que também se expande ao virtual e digital [...] (RUTSCHILLING, 2008, p. 43-44). Ou seja, hoje essa área deve ser compreendida para além de projetos bidimensionais; pois, a tridimensionalidade tem se tornado uma característica expressiva e também muito explorada em projetos inovadores.

Nesse panorama, utilizar de outras potencialidades técnicas, bem como, das tecnologias digitais para a produção de novas ideias para essa área, é compreender que estamos diante de diferentes possibilidades de trabalho contemporâneas. Portando, é inserido nessa linha de pensamento que está apresentado abaixo, o experimento realizado durante a pesquisa de doutorado. Algo que considerou a importância de se articular novas formas de criação ou conferência de qualidade visual à superfície.

\section{TEXTILSKIN: um experimento}

A Textilskin é um espaço digital que promove o desenvolvimento visual de módulos - elemento imagético que possui toda a informação visual que será utilizada no sistema de repetição - rapport. De forma randômica, os elementos visuais são combinados no sistema operacional para que esses módulos, coloridos ou não, apareçam. Propõe ao interator um jogo de escolhas pessoais, onde é possível responder perguntas determinadas no site através da seleção de números correspondentes à sua idade, o seu peso ou à sua altura. Assim, os elementos visuais, já codificados, vão sendo combinados aleatoriamente pelo sistema computacional, até chegar ao resultado final, quer seja, uma imagem com composição de elementos gráficos.

Esses elementos, previamente codificados em swf - Shockwave Flash - formato de arquivo para aplicação web, com característica para suportar conteúdo multimídia, ou foram criados pela pesquisadora ou foram enviados pelo próprio usuário no formato vetorizado; ou seja, desenhado a partir da utilização de algum software de edição de imagem.

Esse espaço foi registrado como www.textilsk.com. O seu lançamento ocorreu no mês de novembro, no ano de 2011. E, possui três versões de atualização. Para que o site funcione, o usuário precisa se conectar no Facebook - espaço utilizado como suporte para que haja ampliação e maior divulgação entre usuários de diferentes lugares. No site, o usuário é direcionado por perguntas que foram escolhidas de forma pessoal e lúdica pela pesquisadora, e são elas: Qual a altura do seu humor? Qual a 
idade do seu sorriso? Qual o peso da sua felicidade? Quando te vê parece? Sou? Cartela de cores (paisagem).

Dentro dessa proposta experimental, o desenvolvimento prático do trabalho foi pensado como, segundo Maturana e Varela, (1997), explicaram: um sistema dentro do paradigma biológico, de máquinas autopoiéticas, que mantém algumas variáveis constantes como garantia de sua existência, mas se retroalimentando do meio que o rodeia, de tal forma que os dados de saída afetam sua entrada, ou seja, na base de sua organização está o meio circundante, aqui representados pelos usuários, e o meio de retroalimentação serviço feito pela tecnologia digital (MATURANA \& VARELA, 1997, p. 70-71). Desse modo, "Para ampliar os limites da tecnologia e de seu uso é preciso pensar as relações entre tecnologia e processo de conhecimento; tecnologia e processo criador" (BARBOSA, 2005, p. 111). Assim, os processamentos das informações digitais, no caso dessa investigação sobre a cocriação e geração de imagens, envolvem qualidades imateriais numéricas que podem ser transmitidas por meio de dispositivos diversos - computador, smartphones, Ipads, entre outros, configurando um processo criativo expandido. Algo que se transforma constantemente e de forma coletiva.

Desde o início, esse experimento foi implementado para funcionar utilizando o Facebook como suporte de divulgação e a ampliação da rede de usuários que poderiam compartilhar os seus módulos gerados. Contudo, essa rede, agora, no mês de março, do ano de 2014, bloqueou esse experimento. Não há mais permissão que o usuário, logado na Textilsin e no Facebook, publique os módulos. Isso tem acarretado o funcionamento parcial do trabalho. A coleção de módulos gerados pelo usuário não pode mais ser visualizada pelo sua rede amigos, em tempo real. Entretanto, a função de geração dos módulos está funcionando normalmente.

Para a codificação do sistema operacional desse experimento foram combinados, de maneira aleatória, elementos figurativos, como linhas, círculos, quadrados, árvores, flores, entre outros elementos enviados pelos usuários; com números referentes ao peso, altura e idade, combinados também com a forma em que tais elementos surgiriam no espaço digital, como, por exemplo: na posição de gradação, radiação ou equilíbrio. A tabela 1 abaixo demonstra como foram articuladas as informações definidas para o funcionamento da geração visual hoje constituída no site.

QUADRO 1. Quadro de variações numéricas em relação à posição dos elementos visuais gerados pela ferramenta Textilskin. 


\begin{tabular}{|c|c|}
\hline Figuras Geométricas relacionadas & $\begin{array}{l}\text { Princípios do Desenho conforme código } \\
\text { numérico estabelecido }\end{array}$ \\
\hline Círculo, árvores, flores & $\begin{array}{c}\text { Gradação - } 00 \\
\text { Radiação - } 100 \\
\text { Repetição - } 00 \\
\text { Equilíbrio - } 00 \\
\text { Concentração - } 00\end{array}$ \\
\hline Quadrado, bonequinhos, frutas & $\begin{array}{c}\text { Gradação - } 00 \\
\text { Radiação - } 10 \\
\text { Repetição - } 100 \\
\text { Equilíbrio - } 20 \\
\text { Concentração - } 50\end{array}$ \\
\hline Triângulo, vestido, tesoura, folhas & $\begin{array}{c}\text { Gradação - } 100 \\
\text { Radiação - } 50 \\
\text { Repetição - } 10 \\
\text { Equilíbrio - } 00 \\
\text { Concentração - } 70\end{array}$ \\
\hline $\begin{array}{l}\text { Todos os elementos enviados } \\
\text { pelos usuários }\end{array}$ & $\begin{array}{c}\text { Gradação - } 50 \\
\text { Radiação - } 50 \\
\text { Repetição - } 50 \\
\text { Equilíbrio - } 50 \\
\text { Concentração - } 100\end{array}$ \\
\hline
\end{tabular}

Fonte: "Dados elaborados pelo autor com base na pesquisa realizada".

Portanto, dentro de um sistema combinatório de dados, foram escolhidas arbitrariamente as relações que surgem no site. À medida que o usuário escolhe 0 número 0 para todas as respostas, há uma forte tendência a surgirem mais flores no módulo no sentido da gradação, do que outro elemento visual. Contudo, se as respostas tiverem maioria o número 100, por exemplo, o módulo tenderá a ter quase todos os elementos visuais dispostos na forma concentrada ou em gradação. Mas, isso não indica que seja regra geral para o funcionamento do site. Como o trabalho possui - aspecto randômico como alicerce, os resultados visuais podem variar constantemente, oferecendo sempre novas combinações visuais.

\subsection{Resultados visuais gerados no site}

A imagem da figura 1, abaixo, é a interface gráfica que apresenta a geração do módulo que o usuário poderá publicar em qualquer tipo de rede. Isso, após salva na coleção de módulos. Nessa primeira etapa, o usuário encontra as perguntas que o direcionam para o desenvolvimento do módulo, em seguida, do lado direito da tela, encontra o ícone gerar textura; após a geração do módulo, o usuário pode do lado 
esquerdo desse quadrado central, retirar elementos visuais que não lhe agradar, e do lado direito estão as funções visualizar, mudar a cor e salvar.

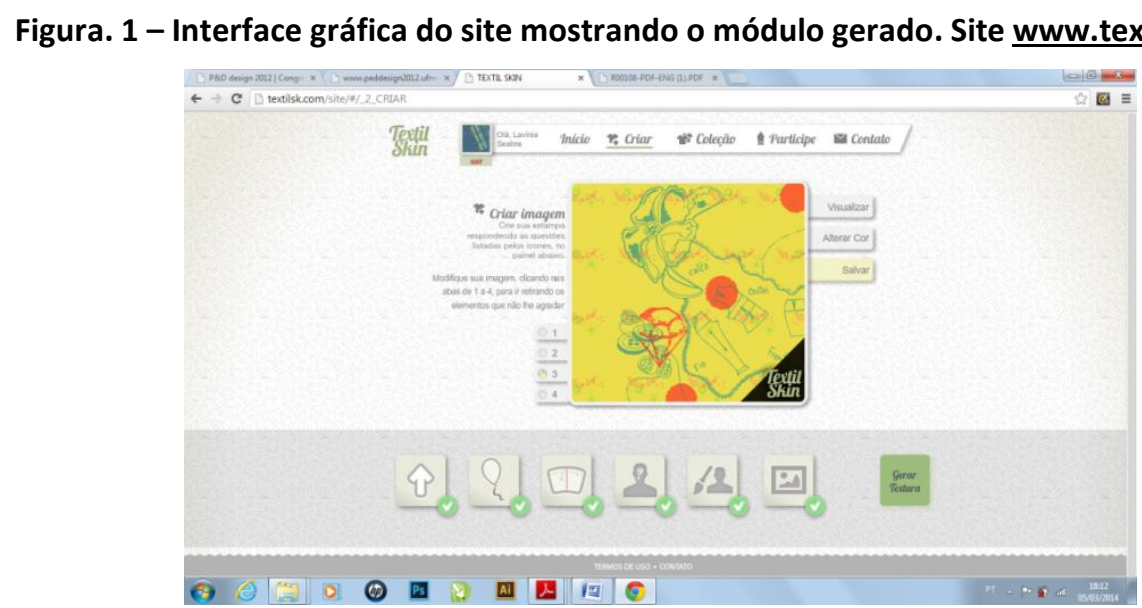

Fonte: "Elaborado pela pelo autor com base na pesquisa realizada".

A figura 2 abaixo é a demonstração da segunda interface do site. Apresenta a repetição (rapport) do módulo gerado. Ao clicar no ícone salvar, ainda na primeira interface, o usuário é direcionado para essa etapa, onde há cinco possibilidades de repetição do lado esquerdo do retângulo central; e do lado direito, há quatro quadrados com simulações de algumas texturas para que a repetição escolhida possa ser vista. Abaixo do retângulo central, o usuário ainda encontra outros três objetos para que possa visualizar o módulo gerado.

Figura. 2 - Módulo repetido no site www.textilsk.com

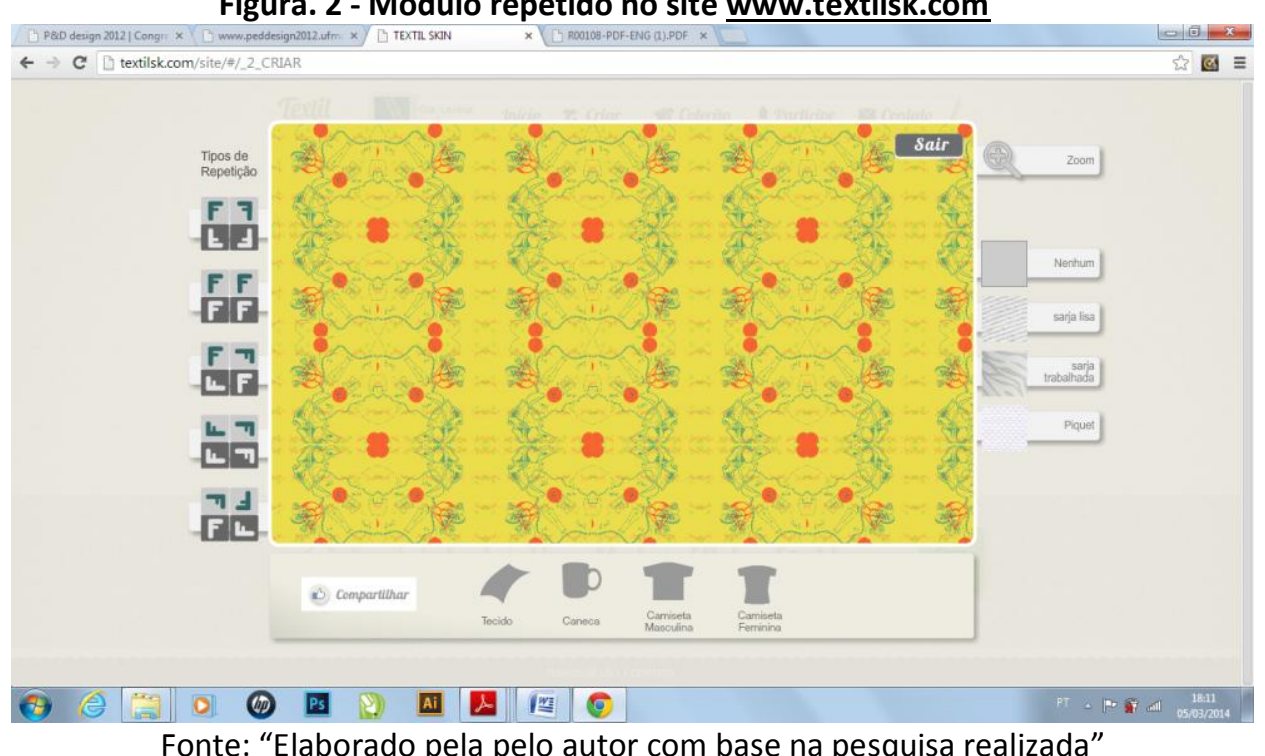

Já, a figura 3, abaixo, mostra como o módulo era publicado no ambiente da rede social Facebook. 
Figura. 3 Módulo gerado na Textilskin e publicado na interface da pesquisadora no FACEBOOK.

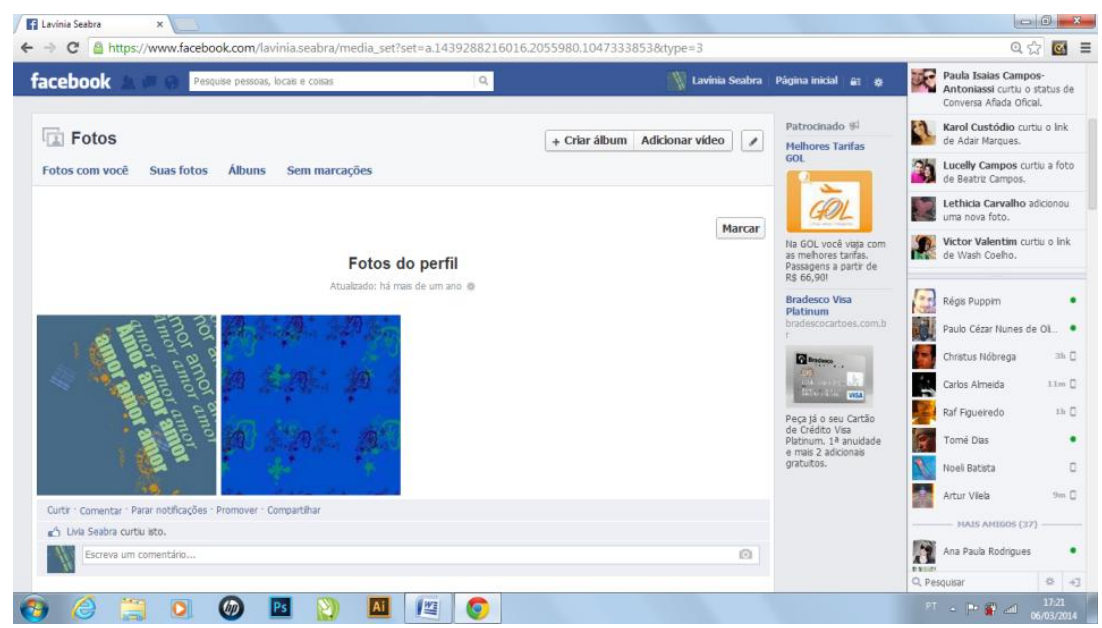

Fonte: "Elaborado pela pelo autor com base na pesquisa realizada".

Assim, a TEXTILSKIN proporciona atualmente:

- Formação de padrões imagéticos;

- Retirada ou não de elementos nesses padrões;

- Mudança de cores utilizando a cartela de cores oferecidas no site e representadas por fotos, também, escolhidas aleatoriamente;

- Combinação aleatória de elementos gráficos;

- Visualização do padrão em diferentes formas de repetição - rapport;

- Possibilidade de visualização do padrão gerado em peças de vestuário - T-shirts e tecidos, ou seja, simulação de aplicação em produtos;

- Incorporação da contribuição de usuários - através de envio de arquivos no formato vetor.

\section{CONCLUSÃO}

Desde o lançamento da Textilskin, no ano de 2011, mais de 1000 usuários interagiram com sua interface gráfica. E, para que houvesse essa análise quantitativa, o site foi cadastrado no sistema de análise estatística da google Google Analitcs que mensura a evolução de sites, como: a quantidade de usuários que interagem; as regiões de onde esses usuários são; a capacidade de crescimento desse site; a proporção de usuários que retornam ou não, para a visitação no site; entre outros aspectos.

$\mathrm{Na}$ versão atual, foi possível envolver 300 usuários efetivos que cocriaram e contribuíram para melhorias futuras. Para a identificação dessa colaboração efetiva e análise dos dados visuais, foi unificado, junto ao sistema criado, outra página web, com a função de administrador dos dados, que permitiu acesso à quantidade de módulos gerados por cada usuário e, ainda, controle sobre as imagens enviadas por eles. Com essa possibilidade, foi possível identificar a geração de três módulos visuais diferentes, por cada usuário, pelo menos; bem como, o envio de um desenho vetorizado por parte de 100 usuários. Nesse contexto, foram gerados 900 módulos e, mais de 1000 possibilidades de combinações visuais a partir dos 
elementos imagéticos criados, tanto pela pesquisadora quanto pelos usuários que enviaram suas imagens vetorizadas.

Com esses resultados, foi possível alcançar um dos objetivos do experimento, a experimentação de uma nova forma de se pensar o desenvolvimento criativo de imagens possíveis de aplicação em objetos cotidianos. Algo com suporte na rede digital de pessoas conectadas e interagindo em tempo real umas com as outras.

Por outro lado, as avaliações de alguns usuários e da própria banca realizada para a defesa da tese, indicam que, para que essa ferramenta virtual se torne passível de utilização em práticas educativas de cursos de Design e na própria indústria, precisa ser desenvolvida em rede social aberta, onde não haja restrição de uso, como acontece no Facebook. Foi apontado, transformá-la numa rede aberta de criação visual. Isso, desde que se torne mais rápida e possa permitir a interferência de qualquer usuário na formação dos elementos visuais gerados, como acontece no exemplo do WIKIPAINT. Outro aspecto sugerido é permitir que essas imagens geradas possuam maior qualidade na resolução final para impressão direta em substratos, sem o tratamento em outro software de manipulação de imagem; e, ainda, que as possibilidades de repetição sejam exatas sem falha no momento da combinação dos módulos.

Assim, esses aspectos já estão sendo realinhados para que, no ano de 2015, o site possa de fato, sair do experimentalismo e alcançar outras possibilidades de aplicação. Todavia, já foi possível perceber, considerando as análises descritas na tese, que muitos trabalhos cocriativos podem ser concebidos no ambiente virtual digital, podendo se pensar numa aplicação muito produtiva para o Design de Superfície. Mesmo em sendo um experimento, o trabalho aqui exposto, conseguiu aliar conhecimentos transdisciplinares que são essenciais para o desenvolvimento de inovações.

\section{REFERÊNCIAS}

CASTELLS, Manuel. A Sociedade em Rede. Tradução de Roneide Venâncio Majer com colaboração de Klauss Brandini Gerhardt. São Paulo: Editora Paz e Terra, 2008.

DELEUZE, Gilles e GUATTARI, Félix. Mil platôs: capitalismo e esquizofrenia, tradução de Aurélio Guerra Neto e Célia Pinto Costa. vol. 1. Rio de janeiro: Ed. 34, 1995.

DONATH, J. Identity and deception in the virtual community. In: KOLLOCK, P.; SMITH, M. (Orgs). Communities in Cyberspace. London: Routledge, 1998.

GARTON, L; HAYTHORNTHWAITE , C. e WELLMAN, B. Studying Online Social Networks. Journal of Computer Mediated Communication, n. 3, vol 1, 1997.

DE FRANCO, Augusto. Cocriação: reinventando o conceito. Disponível em: <http://nethcw.ning.com/page/co-criacao-reinventando-o-conceito> Acesso em 13/04/2014.

MATURANA, Humberto. De máquinas e seres vivos: autopoiese- a organização do vivo. Porto Alegre: Artes Médicas, 1997.

PRAHALAD C. K. AND VENKAT Ramaswamy. Co-creation experiences: the next practice. IN: VALUE PRATICE. Disponível em:

<http://deepblue.lib.umich.edu/bitstream/2027.42/35225/1/20015 ftp.pdf> Acesso em 13/04/2014.

PRIMO, Alex. O aspecto relacional das interações na Web 2.0. E- Compós (Brasília), v. 9, p. 1-21, 2007. Disponível em: <http://www.ufrgs.br/limc/PDFs/web2.pdf> Acesso em 13/04/2014. 
RECUERO, Raquel. Redes Sociais na Internet. Porto Alegre: Sulina, 2009.

RHEINGOLD, Howard. La Comunidad Virtual: Uma Sociedade sin Fronteiras. Gedisa Editorial. Colección Limites de La Ciência. Barcelona 1996.

RUTHSCHILLING, Evelise Anicet. Design de Superfície. Porto Alegre: Editora da UFRGS, 2008.

SANTAELLA, Lúcia \& LEMOS, Renata. Redes Sociais Digitais: a cognição conectivaa do Twitter. São Paulo: Paulus, 2010. 